\title{
The Cost of Hope: A Candid Roundtable Discussion
}

Presented by Amanda Bennett; Ronald M. Bukowski, MD; Keith Flaherty, MD; J. Cameron Muir, MD; and Craig D. Turner, MD; moderated by Sam Donaldson

\begin{abstract}
For Amanda Bennett and her husband Terence Foley, a 7-year battle with kidney cancer resulted in a price tag of more than $\$ 600,000$, most of it spent in the final 2 years of his life. Ms. Bennett's memoir, The Cost of Hope, chronicles the couple's emotional struggle and the financial irrationality she uncovered when navigating the cancer continuum. She shared her experience in her keynote address at the NCCN 18th Annual Conference, which was followed by a roundtable discussion in which panelists discussed the difficulties inherent in dealing with cancer "uncertainties," the balancing act that seeks to maintain hope in the context of a poor prognosis, and the problem of a health care system that spends too much on some aspects of care while ignoring others. (JNCCN 2013;11:633-635)
\end{abstract}

Sam Donaldson, ABC News veteran and anchor, in his seventh year as moderator of the opening roundtable discussion at the NCCN 18th Annual Conference, began the session by posing questions: "We all want optimistic doctors, but can they be misleading? At what stage does tough love have to be presented to the patient - if not accepted? Where is the line drawn between optimism and realism and between hype and hope?"

\section{The Need for Hope}

Amanda Bennett, a Pulitzer Prize-winning journalist, wanted to believe her husband Terence Foley could fight kidney cancer and win — even as he was clearly dying. She believed that if she were "strong enough, smart enough, and worked hard enough," she and his "brilliant physicians would keep him from dying-ever! I felt it was my job," she added. "I still felt that up until a few days before he died."

Although false hope may have played a role in starting medical care that was too aggressive at the end of life, she explained, "Hope was good for us, without question. It changed what should have been the 7 worst years into the 7 most wonderful years."
Keith Flaherty, MD, Director of Developmental Therapeutics for the Massachusetts General Hospital Cancer Center, who enrolled Mr. Foley in clinical trials when standard treatment failed, added that physicians have their own "inflation of hope."

"In the medical community, we tend to attach a lot of optimism to new therapies and think they will have a bigger impact in our clinical practice than we saw in the trials. That was the situation with Terence," he said. He noted that when Mr. Foley was symptomatic, "which worried me in terms of his longevity, we had this brand new shiny drug. ... Should we have shifted the conversation at this juncture? Indeed."

\section{The Uncertain World of Cancer}

J. Cameron Muir, MD, Executive Vice President for Quality and Access at Capital Caring and a palliative care specialist, said this experience is typical. "Patients come to the physician under the assumption that they are curable," he said. When the prognosis is not good, the physician's responsibility to maintain hope while being truthful is "a delicate balancing act" that involves hoping for the best but preparing for the worst, he said.

The concept of "uncertainty," he said, is part of the challenge for all parties. One of those uncertainties is that treatment options will provide uncertain benefit for the individual patient - a "realm of gray" that is uncomfortable to physicians, he said.

Patients clearly find uncertainty to be discomforting as well, according to Ms. Bennett. "If we are operating in a world where we want and need certainty, then uncertainty will be unsatisfying. If we accept uncertainty, we can adapt," she offered. Nevertheless, she added that if she had understood the degree to which the efficacy of interleukin-2 was uncertain though its toxicity was certain, her husband might have chosen to 


\section{One Family's Story, Eloquently Told}

For Amanda Bennett and her husband Terence Foley, the "cost of hope" carried a more than half-million-dollar price tag for treatment that, in the end, proved unable to save his life after a 7-year battle with kidney cancer.

Ms. Bennett, executive editor for Bloomberg News and a Pulitzer-Prize-winning journalist, documented this cancer journey in her book, "The Cost of Hope: A Memoir," about her husband's cancer and her effort to make sense of the health care system they navigated across the course of care. She delivered the keynote address at the NCCN 18th Annual Conference and was joined in a panel discussion by several of her late husband's physicians.

Mr. Foley's tumor, variously diagnosed as collecting duct carcinoma and papillary renal cell carcinoma, was an incidental finding in 2000. Within about 1 year, the kidney cancer had metastasized to the lung. Mr. Foley received the appropriate treatment for the time, interleukin-2, but discontinued 6 weeks later due to toxicity. Because the tumors appeared fairly indolent, his oncologist proposed a watch-and-wait approach to spare him further toxicity.

His disease was stable for 3 years but eventually progressed. He entered a clinical trial of sorafenib plus bevacizumab. The tumors responded to the regimen for a while, and when his cancer again progressed in 2007, an experimental drug at the time - sunitinib - seemed a reasonable option. "I told his physician, keep him alive if you can, which is what most of us would say. He died 6 days later," Ms. Bennett said.

The cost of Mr. Foley's cancer care totaled $\$ 618,616$, and nearly two-thirds of this cost was incurred in the final 2 years of his life. In fact, 4 days before he entered hospice care, his insurance paid $\$ 43,711$ for drugs, scans, laboratory tests, and physicians' fees.

"The first 5 years, costs averaged $\$ 130$ a day. In the final week of his life, the average hit $\$ 8,000$ a day. As the financial cost skyrocketed, so did the emotional cost," she said.

"I had the best insurance available, and nothing was denied," she noted. With a focus on keeping Terence alive, no price seemed too high. In retrospect, Ms. Bennett questioned the rationality of cancer costs gone wild. "A year after his death I was left wondering whether we had done the right thing: enough, too little, too much? It occurred to me I could try to find out."

The result of this exploration is Ms. Bennett's memoir, which describes her quest to make sense of contemporary cancer treatment and the personal and financial costs of that care. "It's complex to navigate this system. It took years to figure it out and leaves me today not entirely sure we did the right thing," she admitted.

She said the current system forced her to be a "general contractor" who located a doctor for every problem but never identified one "just interested in him." At some point, they saw 27 healthcare specialists in 4 days, including 9 physicians. "I found myself asking, who is the boss here? And I didn't get an answer."

Looking back, she said, "Some lessons were big and profound, some were small and technical, and some were outright contradictory. Why was the system designed for doctors, hospitals, laboratories, technicians, and insurance companies and not for Terence and me? Had it been designed for us, would we have been better off, made more rational decisions? I think so."

\section{forego that treatment.}

Communicating the chances of a good versus poor outcome with a given treatment is challenging for physicians, however. For example, Dr. Flaherty noted, quoting disease-related statistics to patients is difficult. Physicians can say, "We have a sense of how 100 people with this diagnosis may do over 5 and 10 years," he noted. This is helpful to doctors, but the individual patient wants only to know whether the cancer will recur, he said. "It's binary for them."

Craig D. Turner, MD, Board-certified urologist with Urologic Consultants, PC, and the urologic surgeon who removed Mr. Foley's kidney and was involved in his initial cancer diagnosis, said "uncertainty" is also very hard for surgeons, who think in terms of "black and white." All patients are different, and Mr. Foley had "his cancer," he said. "It's individual. I tell my patients that their chance of cure is zero or $100 \%$, and I can't tell them which, but until I have evidence to the contrary, I will be optimistic." Dr. Muir agreed, "For the patient, this experience is 'an $\mathrm{N}$ of 1,' not a statistic."

The important thing, the panelists agreed, is that the topic be broached to a degree that is comfortable for patient and physician. To Ronald M. Bukowski, MD, principal for Bukowski Consulting, LLC, who treated Mr. Foley at the Cleveland Clinic, "There is no one way to do this. It depends on the physician and on the patient. You have to consider how patients are considering their illness and what they want to hear."

Dr. Muir added that data from the hospice and palliative care settings show that "if you facilitate such 
discussions, you help the patient get the right care at the right place at the right time, and it also ends up costing less."

\section{The Financial Cost of Hope}

For Ms. Bennett and Mr. Foley, maintaining hope cost "much more than it should have," she said. "Had we known the cost, we may have made other decisions, but it [cancer care] was free to us, so we could always have the next treatment. For many other people, the expense of treatment puts hope out of reach."

Once her husband died and she began the research that informed her book, Ms. Bennett looked more closely at the financing of her husband's treatment and concluded, "We have designed a billing system that is operated by Satan."

As her employer and therefore her insurance benefits changed over time, she saw that the cost of the same procedures varied tremendously from bill to bill. One CT scan cost $\$ 800$, while another cost $\$ 2400$. "It was a matter of which insurance company negotiated the cost," she explained.

It also represented overtreatment, she added. Mr. Foley underwent 76 CT scans over 7 years. "Were they all necessary? Of course not. Could it have been cut in half? Probably," she figured. "Everyone wanted to know a little more for his or her purposes, without knowing or caring what they cost. We pop these expensive treatments like Kleenex."

Dr. Turner said that the cost of treatment is not only a key consideration in his own mind now, but part of the conversation with his patients. Dr. Flaherty agreed, especially when patients have a 20\% copay and are receiving an expensive biologic agent.

In Dr. Bukowski's experience, most patients do not directly inquire about the cost of their proposed treatment, and if they did he would have troubling explaining it. "I don't know why things cost what they do." He added that even for those managing cancer centers, getting information on why costs are what they are is difficult. "I don't know that we can fully address the cost issue," he added.

"This is a story of the very, very best of the system, and I learned that there is still a lot to be desired," Ms. Bennett concluded.

\section{End of Life}

She also now sees as unreasonable the fact that so much expense was incurred at the end of life. In retrospect, she would have liked to have seen palliative care integrated earlier in her husband's treatment. "That's what we needed," she acknowledged. "It was mentioned to me, but I didn't believe he was dying."

"We have a noble path for curing disease, but there is no noble path for letting go," she commented. "Dying is seen as failing."

Because no one wants to "fail," denial is not only a common reaction for patients and their loved ones but for health care providers as well, Ms. Bennett maintained. "You want to help, to fix, to make it better. Having a patient die must seem like a failure. Terence's physician said just 3 weeks before he died, that I should tell him that better days are ahead. I think all 3 of us believed that." This denial, she said, robbed them of the opportunity to say goodbye before he entered hospice care. "We weren't prepared," she said.

Dr. Muir added, "The patient is part of a family unit, and they all have hopes, dreams, and goals. These all need to be discussed and understood better... so you can create a shared understanding and path." He said he has been struck by how "magical experiences in the face of death" can happen when this discussion takes place. "A terminal diagnosis can bring up the preciousness of time," he said.

\section{Meet the Panelists}

Sam Donaldson: $A B C$ News veteran and anchor.

Amanda Bennett: Pulitzer Prize-winning journalist, executive editor for Bloomberg News, and author of The Cost of Hope: A Memoir.

Ronald M. Bukowski, MD: Principal for Bukowski Consulting, LLC, consultant and emeritus staff physician at the Cleveland Clinic Taussig Cancer Center.

Keith Flaherty, MD: Director of Developmental Therapeutics for the Massachusetts General Hospital Cancer Center, Boston, and principal investigator for first-in-human trials of BRAF inhibitors.

J. Cameron Muir, MD: Executive Vice President for Quality and Access at Capital Caring in Falls Church, Virginia; Past-President of the American Academy of Hospice and Palliative Medicine.

Craig D. Turner, MD: Board-certified urologist with Urologic Consultants, PC, of Portland, Oregon, with a special interest in surgical innovations. 